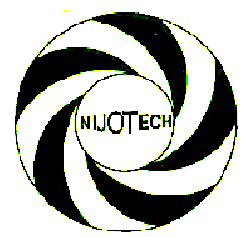

Nigerian Journal of Technology (NIJOTECH)

Vol. 33. No. 3, July 2014, pp. 245 - 251

Copyright@ Faculty of Engineering,

University of Nigeria, Nsukka, ISSN: $1115-8443$

www.nijotech.com

http://dx.doi.org/10.4314/njt.v33i3.1

\title{
ASSESSMENT OF LONG-RUN MARGINAL COSTING OF TRANSMISSION AND DISTRIBUTION EXPANSION
}

\author{
A. O. Ekwue*

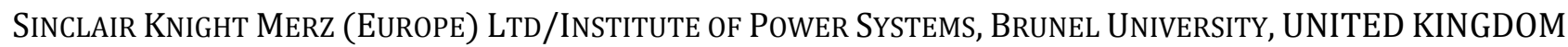 \\ E-mail address: arthur.ekwue@brunel.ac.uk
}

\begin{abstract}
The Long-Run Marginal Costing (LRMC) technique is used as a cost-reflecting pricing method and finds useful application in the recovery of the total investment cost for the use of a transmission or distribution network. This paper reviews recent applications of this technique based on some examples from United Kingdom, Greece and Oman. Then using typical practical networks as case studies, this paper compares two different methods for the determination of the LRMC of transmission and distribution expansion/reinforcement: the average incremental cost (AIC) methodology and marginal incremental costs (MIC) techniques. Based on the results obtained, it is concluded that the AIC technique is easier to implement and explain because of its price stability.
\end{abstract}

Keywords: transmission planning, distribution planning, power system economics, long run marginal costing, application and design studies

\section{INTRODUCTION}

Basic economic theory proposes that prices should be set at marginal cost (MC) as it maximizes social welfare and provides appropriate cost signals to the consumer. MC can be classified as either long-run (LRMC) or short-run (SRMC). LRMC can be defined as the cost of supplying an extra $\mathrm{kW}$ of electricity to a consumer during system peak whereas SRMC is the cost of the most expensive generating plant to run required to meet the hourly demand; this results from congestions and constraints in the network. Previous studies [1] have concluded that the SRMC is not appropriate for transmission pricing, because it tends to reward a network utility when its performance deteriorates (e.g. due to increased losses and congestion), which creates perverse incentives for the utility regarding new investments and maintenance practices. Secondly, SRMCs are considered very volatile depending on the prevailing system conditions.

It is well recognized that the LRMC principle is widely used as a cost-reflecting pricing technique and finds useful application in the recovery of the total cost of the use of the network. For example, the first stage in a tariff study is to determine the resource costs (known as the long run marginal costs - LRMC) of supplying electricity. These are determined by estimating the capital and operating costs of expanding the power supply at the generation, transmission, and distribution levels. The LRMC can be used to calculate the total cost of ownership, to find least cost solutions for overhead line, cable and transformer sizing, the justification of timing new investment in transmission and distribution facilities versus consumer outage costs etc.

In general, the cost of electricity will rise as the voltage of supply falls. This is due to both the extra investment required at each voltage level and the incremental losses as electricity is transformed and transmitted throughout the system. Costs will also vary by time of day and by season as well as by the load characteristics of individual consumer groups. Moreover it is important to encourage the reduction of electricity consumption during the peak hours so that in the long run, reduction in generation, transmission and distribution investments will be realized.

The objectives of this paper are:

- to review international developments in LRMC for transmission and distribution system expansion; this is covered in Section 2 of the paper.

*Author's Telephone: +44(0)7535267242. The views expressed in this paper are those of the author and do not represent those of Sinclair Knight Merz (Europe) Limited London or Brunel Institute of Power Systems, Brunel University (UK) 
- to use typical practical networks as case studies and compare four different methods for the determination of the LRMC of transmission and distribution expansion/reinforcement: the average incremental cost (AIC) methodology and marginal incremental costs (MIC) techniques; this is presented in Section 3. Though the methods differ mainly in the way the transmission and distribution system capacity increments are evaluated, the paper will investigate under what condition it is best to use each technique. This is discussed in Section 4 of the paper.

- Two case studies for transmission and distribution networks are presented in Section 4 of the paper.

\section{PRACTICAL INTERNATIONAL IMPLEMENTATION OF THE LRMC TECHNIQUE}

There has been many papers produced on the LRMC technique but the author will review some practical developments since 2000 .

Turvey in a seminal paper [2] provided a detailed analysis of the theory and principles of MC as well as its application to several regulated industries such as electricity (comprising of generation in thermal, hydro, mixed hydro-thermal systems, transmission and distribution); gas transmission, water supply and railways. The paper was a further development of the work of the author published in 1969 and he defined MC as "an estimate of the effect upon the future time stream of outlays of a postulated change in the future time stream of output". MC has always been preferred by economists as a pricing methodology since it maximizes social welfare. The main advantages of LRMC technique are:

* it provides correct price signals for network services to consumers;

* less volatile;

* generates investment costs for future growth of electricity demand;

LRMC pricing has been used in countries such as Tunisia, Chile, Pakistan and Sri Lanka and other countries. Some specific international experiences in UK, Greece and Oman follow:

\subsection{United Kingdom}

The National Grid Company (NGC) initially considered and rejected the LRMC in 1992 for their Use of System Charges Review because [2]:
* though relatively accurate load forecasts were available, the future generation assumptions used (both for new plants and closures) in the development of the NGC's long-term development plan (otherwise known as the Seven Year Statement) cover a much shorter period and may not be realised in practice. Therefore it was difficult to establish a realistic base scenario.

* LRMC is highly sensitive to the size of demand and generation changes assumed.

* detailed system planning studies similar to those carried out in comprehensive electricity master plan developments would be required investigating changes in generation and transmission scenarios. The number of possible combinations of alternative scenarios would be computationally expensive for the NGC system with hundreds of nodes.

This example exposes the problems of applying LRMC methodology to large transmission systems in developed countries. Based on the author's experience, this is no longer a hindrance having being involved in the development of electricity master plans recently in developing countries. However, later that year (1992), NGC estimated LRMC by "comparing differences in investment costs between two scenarios and a base case with the differences in revenue yielded" via their in-house algorithm: Investment Cost Related Prices technique based a simple transport model [2].

Considering distribution networks, the University of Bath and Western Power Distribution Company recently developed the Long-Run Incremental Pricing (LRIC) methodology [3]. The technique was found to be sensitive to the rate of growth of demand. Though the initial formulation assumed that the load growth is fixed in the future, this is not a realistic practical assumption because the future load growth of any utility is uncertain; it depends on the imprecise nature of a country's economic policies, markets and regulatory policies etc. Hence Li et al [4] extended their original works to model uncertain characteristics of load growth using fuzzy load growth rate. A further enhancement has also been described to consider positive, negative and zero circuit growth rates [5]. The main incentive was to cater for cases with different demand and generation growth rates. The growth rate will be positive for corresponding growth in generation and demand; a negative growth rate will be when the demand grows 
faster than the generation or in cases when the demand decreases. Finally a zero growth rate is where the circuit loading level remains the same and this will result when both the demand and the generation are neither decreasing nor increasing.

\subsection{Greece}

The SRMC could not be used solely to price transmission services because the collected revenues could not cover the revenues required by the transmission owners due to economies of scale in transmission [6] hence the adoption of the LRMC technique. The calculation of LRMC of transmission used for determining the use-of-system tariffs (TUoS) for the Public Power Corporation of Greece was based on the sensitivity analysis around the solution of the problem of constructing the optimum transmission network. Two methods based on Investment CostRelated Pricing similar to the NGC model and DC Load Flow Pricing were employed. The paper concluded that the methods provided appropriate economic signals for the location of new generators in the South of Greece and new loads in the North. In many cases, though, the Investment Cost-Related Pricing technique led to greater differentiation of charges between TUoS zones. Both methods provided the same ranking of the zones with respect to generation tariffs. In the end the DC Load Flow Pricing technique was finally selected as it resulted in realistic power flows though it required more input information.

\section{$2.30 \mathrm{man}$}

In a paper [7], the AIC technique was used to calculate the LRMC for transmission and distribution expansion network of their Ministry of Housing, Electricity and Water interconnected power system in Oman. A major incentive for this work was that the electricity tariffs were highly subsidized and based on cost accounting methods which did not reflect the true costs of delivering electricity to the consumers. From the results obtained, it was concluded that the proposed LRMC-based tariffs will ensure financial viability in the power sector. Secondly the customers should be charged based on the burden put on the electricity network.

The LRMC principle is widely used as a cost-reflecting pricing technique and finds useful application in the recovery of the total cost of the use of the network. The practical application of the some variants of the LRMC for the electricity industry has been demonstrated in a few countries above. The technique finds useful applications in several regulated industries such as gas transmission, water supply and railways as demonstrated in [2]. Additionally the use of the technique for the pricing of water services by the Gladstone Area Water Board of Queensland Completion Authority was described in [8]. That Report mentioned other users as UK's Water Services Regulation Authority (Ofwat); Canadian Water and Wastewater Authority and the World Bank.

In the next Section two LRMC techniques are defined: the average incremental cost (AIC) methodology and marginal incremental costs (MIC) techniques. These are applied to two practical networks in Section 4 and compared.

\section{CALCULATIONS}

\subsection{Marginal Incremental Costs (MIC)}

Marginal Incremental Costs can be defined as "the difference in the present values of the investment programs with and without an incremental increase in demand" [8] and can be evaluated as follows:

* Forecast the electricity demand for the entire planning period;

* Estimate the network (transmission or distribution) investment costs required of a series of augmentations over the planning period.

* Calculate the MIC for each stage of the investment period as explained below.

Two variants of the MIC technique were developed as follows:

From reference [8], Technique 1 is given by:

$$
\text { MIC }=\frac{\text { change in NPV of investment cost }}{\text { incremental electricity demand within that period }}
$$

where NPV stands for Net Present Value

Two variants of this method can be defined as

Technique 2:

$\mathrm{MIC}=\frac{\text { changein NPV of investment cost }}{\text { changein NPV of demand growth }}$

and Technique 3:

MIC $=\frac{\text { NPV of investment cost }}{\text { NPV of demand growth }}$

The intermediate annual operation and maintenance charges are included in the upgrade costs.

\subsection{Average Incremental Costs (AIC)}

This is obtained by discounting the transmission investment costs required over the planning period and dividing that by the discounted value of the growth in electricity demand over the planning 
period. The AIC is similar to Technique 3 of the MIC above except that this is evaluated over the planning period under consideration.

\section{CASE STUDIES}

\subsection{Case Study 1 - Transmission Network}

Consider a transmission network with three main transmission investment costs considered over a period, 2005 to 2025 , were incremental transformer costs required to meet the potential load growth, costs of transmission reinforcement and capacitor costs required to alleviate thermal and voltage constraints.

Load flows were calculated using the Power System Software for Engineering (PSS/E) based on the demand forecasts for 2005 to 2025 and the generation planting program for the same period. For each year, contingency studies were also undertaken to determine if the system is within the design criteria for an outage of one $66 \mathrm{kV}$ or $132 \mathrm{kV}$ circuit. Where the transmission system was found to be operating outside the set criteria, appropriate circuit reinforcements were included. Shunt capacitors were used to improve the power factor in the network as well as reactive power compensation. There are five investment periods in this Case Study. The capital cost and the demand profile are summarized in Tables 1 and 2 .
Table 1: Stages in Transmission Upgrades

\begin{tabular}{lcc}
\hline \multicolumn{1}{c}{ Upgrade } & $\begin{array}{c}\text { Electricity } \\
\text { Demand (MW) }\end{array}$ & $\begin{array}{c}\text { Cost } \\
(\text { \$ in 000) }\end{array}$ \\
\hline Existing network - 2004 & 58.84 & - \\
Upgrade 1 - 2005 & 66.85 & $9,064.6$ \\
Upgrade 2 - 2010 & 99.68 & $7,102.88$ \\
Upgrade 3 - 2015 & 144.33 & $9,313.32$ \\
Upgrade 4 - 2020 & 201.40 & $14,686.5$ \\
Upgrade 5 - 2025 & 274.43 & $8,990.11$ \\
\hline
\end{tabular}

\subsection{Case Study 2 - Distribution Network}

The electricity demand (in MW) for 2009 to 2015 of a typical distribution network was determined following load forecasts in Table 3. This is followed by the $11 \mathrm{kV}$ and 433 volts (LV) circuit lengths and transformer installed capacity for 2009 and 2010; their associated costs per $\mathrm{km}$ or MVA are also required. The costing of the investment required to facilitate the $11 \mathrm{kV}$ and $\mathrm{LV}$ distribution system growth is then determined based on the projected trends for the average $11 \mathrm{kV}$ and $\mathrm{LV}$ circuit length and transformer installed capacity required (in 2011 to 2015) to support load growth on a per MW basis.

Based on the above, there are five investment periods. The capital cost and the demand profile are summarized in Table 4

Table 2: Data for LRMC of Transmission System Expansion [10]

\begin{tabular}{|c|c|c|c|c|c|c|c|}
\hline Year & $\begin{array}{c}\text { Demand } \\
\text { MW }\end{array}$ & $\begin{array}{l}\text { Demand } \\
\text { Growth } \\
(\mathrm{MW})\end{array}$ & $\begin{array}{c}\text { Line } \\
\text { Reinforcement } \\
\$(' 000)\end{array}$ & $\begin{array}{c}\text { Transformer } \\
\text { Costs } \\
\$(' 000) \\
\end{array}$ & $\begin{array}{l}\text { Capacitor } \\
\text { Costs } \\
\$(' 000)\end{array}$ & $\begin{array}{l}\mathrm{O}+\mathrm{M} \\
\$(' 000)\end{array}$ & $\begin{array}{l}\text { Total } \\
\text { Costs } \\
\$(' 000)\end{array}$ \\
\hline 2004 & 58.84 & 0 & 0 & 0 & 0 & 0 & 0 \\
\hline 2005 & 66.85 & 8.01 & 7977.1 & 778.6 & 175 & 133.9 & 9064.6 \\
\hline 2006 & 72.63 & 5.78 & $=$ & $=$ & $=$ & 133.9 & 133.9 \\
\hline 2007 & 78.81 & 6.18 & $=$ & $=$ & $=$ & 133.9 & 133.9 \\
\hline 2008 & 85.42 & 6.61 & $=$ & $=$ & $=$ & 133.9 & 133.9 \\
\hline 2009 & 92.49 & 7.07 & $=$ & $=$ & $=$ & 133.9 & 133.9 \\
\hline 2010 & 99.68 & 7.19 & 4927.98 & 538 & 1400 & 236.9 & 7102.88 \\
\hline 2011 & 107.52 & 7.84 & $=$ & $=$ & $=$ & 236.9 & 236.9 \\
\hline 2012 & 115.87 & 8.35 & $=$ & $=$ & $=$ & 236.9 & 236.9 \\
\hline 2013 & 124.77 & 8.9 & $=$ & $=$ & $=$ & 236.9 & 236.9 \\
\hline 2014 & 134.24 & 9.47 & $=$ & $=$ & $=$ & 236.9 & 236.9 \\
\hline 2015 & 144.33 & 10.09 & 7061.12 & 481.2 & 1400 & 371 & 9313.32 \\
\hline 2016 & 154.48 & 10.15 & $=$ & $=$ & $=$ & 371 & 371 \\
\hline 2017 & 165.22 & 10.74 & $=$ & $=$ & $=$ & 371 & 371 \\
\hline 2018 & 176.6 & 11.38 & $=$ & $=$ & $=$ & 371 & 371 \\
\hline 2019 & 188.65 & 12.05 & $=$ & $=$ & $=$ & 371 & 371 \\
\hline 2020 & 201.4 & 12.75 & 12021.7 & 1557.2 & 525 & 582.6 & 14686.5 \\
\hline 2021 & 214.48 & 13.08 & $=$ & $=$ & $=$ & 582.6 & 582.6 \\
\hline 2022 & 228.28 & 13.8 & $=$ & $=$ & $=$ & 582.6 & 582.6 \\
\hline 2023 & 242.85 & 14.57 & $=$ & $=$ & $=$ & 582.6 & 582.6 \\
\hline 2024 & 258.22 & 15.37 & $=$ & $=$ & $=$ & 582.6 & 582.6 \\
\hline 2025 & 274.43 & 16.21 & 6389.11 & 1019.2 & 875 & 706.8 & 8990.11 \\
\hline
\end{tabular}


Table 3: Data for LRMC of Distribution Network Expansion

\begin{tabular}{|c|c|c|c|c|c|c|c|c|}
\hline Year & 2009 & 2010 & Increase & 2011 & 2012 & 2013 & 2014 & 2015 \\
\hline Distribution network demand forecast (MW) & 236 & 259 & $=$ & 292 & 325 & 361 & 401 & 448 \\
\hline Load growth in MW & $=$ & $=$ & 22.3 & 33 & 33 & 36 & 40 & 47 \\
\hline $11 \mathrm{kV}$ circuit length $(\mathrm{km})$ & 1,262 & 1,326 & $=$ & 96 & 95 & 104 & 116 & 134 \\
\hline Increase in $11 \mathrm{kV}$ circuit length (km) & $=$ & $=$ & 64 & $=$ & $=$ & $=$ & $=$ & $=$ \\
\hline Increase in $11 \mathrm{kV}$ circuit length $(\mathrm{km}) /$ Increase in load & $=$ & $=$ & 2.88 & $=$ & $=$ & $=$ & $=$ & $=$ \\
\hline Cost of $11 \mathrm{kV}$ circuit $(\$ / \mathrm{km})$ & $=$ & 36,750 & $=$ & 38,588 & 40,517 & 42,543 & 44,670 & 46,903 \\
\hline Incremental Cost of $11 \mathrm{kV}$ circuit ('000) & $=$ & $=$ & $=$ & 3,704 & 3,841 & 4,405 & 5,165 & 6,273 \\
\hline 11/0.433 kV Transformer Capacity (MVA) & 961 & 1,084 & $=$ & 185 & 182 & 199 & 222 & 257 \\
\hline Increase in Transformer Capacity (MVA) & $=$ & $=$ & 123 & $=$ & $=$ & $=$ & $=$ & $=$ \\
\hline Increase in Transformer Capacity/Increase in load & $=$ & $=$ & 5.53 & $=$ & $=$ & $=$ & $=$ & $=$ \\
\hline Transformer cost (\$/MVA) & $=$ & 21,000 & $=$ & 22,050 & 23,153 & 24,310 & 25,526 & 26,802 \\
\hline Incremental cost of transformer ( $\$$ in '000) & $=$ & $=$ & $=$ & 4,068 & 4,218 & 4,838 & 5,672 & 6,889 \\
\hline LV circuit length $(\mathrm{km})$ & 1,799 & 1,917 & $=$ & 177 & 175 & 191 & 213 & 247 \\
\hline Increase in LV circuit length (km) & $=$ & $=$ & 118 & $=$ & $=$ & $=$ & $=$ & $=$ \\
\hline Increase in LV circuit length/Increase in load & $=$ & $=$ & 5.30 & $=$ & $=$ & $=$ & $=$ & $=$ \\
\hline Cost of LV circuit $(\$ / \mathrm{km})$ & $=$ & 38,850 & $=$ & 40,793 & 42,832 & 44,974 & 47,222 & 49,584 \\
\hline Incremental cost of LV circuit (\$ in '000) & $=$ & $=$ & $=$ & 7,220 & 7,486 & 8,586 & 10,067 & 12,226 \\
\hline Annual distribution network capital cost(\$ in '000) & & & & 14,993 & 15,545 & 17,829 & 20,904 & 25,387 \\
\hline
\end{tabular}

\subsection{Comparison of MIC and AIC Techniques}

The objective of this Section is to explain the relative complexity and practicality of the different techniques. In the light of the calculations carried out as shown in Table 5 below, the following comparisons can be made between the MIC and AIC techniques:

Table 4: Stages in Distribution Upgrades

\begin{tabular}{ccc}
\hline Upgrade & $\begin{array}{c}\text { Electricity } \\
\text { Demand } \\
(\mathrm{MW})\end{array}$ & $\begin{array}{c}\text { Cost } \\
\text { (\$in 000) }\end{array}$ \\
\hline Existing network- 2010 & 259 & - \\
Upgrade 1 - 2011 & 292 & $1,4992.9$ \\
Upgrade 2 - 2012 & 325 & $15,544.52$ \\
Upgrade 3 - 2013 & 361 & $17,829.0$ \\
Upgrade 4 - 2014 & 401 & $20,903.79$ \\
Upgrade 5 - 2015 & 448 & $25,387.47$ \\
\hline
\end{tabular}

1. The MIC techniques assume that there is always a positive growth in electricity demand. In practice, this may not necessarily be the case as the demand of electricity can go up or down depending on prevailing economic circumstances such as changes in the GDP of a country, weather changes, population etc. Equation (2) is meaningless for zero load growth. Furthermore, the cases of negative load growth need to be explained.
2. Both techniques consider:

- N-1 contingency analysis (for the transmission example described in Case 1)

- positive, negative or zero circuit growth rates (as illustrated in the distribution example described in Case 2). It therefore covers the enhancements described in [3 - 5] in their University of Bath/Western Power Distribution Company LRIC model.

3. The MIC technique considers only the investment periods (over shorter planning periods) whereas the AIC looks at the entire planning period. The MIC becomes more appropriate where a consumer wants to take a one-off decision in any one year.

4. The values obtained for each investment period using the MIC technique vary substantially and therefore difficult to understand and interpret. This complexity increases (with possible negative values as highlighted above) depending on whether the transmission investment costs increase or decrease within the next investment period. This can potentially be abused in explaining its "worth" to the electricity regulator. 
The AIC looks stable over the planning period; it is easy to explain and implement.

5. The AIC technique requires the relationship between the future investment in electricity transmission infrastructure and future growth in electricity demand. It can be said to be "forward" looking. MIC can be calculated based on costs derived in a single year.

6. As a result of the price instability encountered from the MIC techniques, decisions can only be made based on the individual investment period. Therefore the increase or decrease in transmission investment costs due to the need to have more (or less) capacitors and transmission line reinforcements in a previous period will impact on future decision making on possible investments required by a utility. Within a planning period, this may send incorrect signals to the electricity utility. The AIC addresses this uncertainty and has the property to smoothen the price fluctuations.

\section{CONCLUSIONS}

A main contribution of this paper is the comparison of the MIC and AIC techniques to actual transmission and distribution networks derived from master plan development of the electricity infrastructure. This paper has shown that the AIC technique is robust and looks stable over the planning period. It is forward looking being based on the relationship between future investments in transmission and distribution infrastructure and future load growth. The AIC technique has been applied successfully in Oman's Ministry of Housing, Electricity and Water interconnected power system. This supports the views expressed from the World Bank institution in [9] that the method is simple to implement; the results presented in [11] and in this paper confirm this assertion too. In fact, according to [8], the World Bank uses the AIC technique frequently in water supply projects particularly for developing countries. The main disadvantage of the AIC technique described is that it assumes prior knowledge of the generation and demand profile of the network. The inputs to the development of the technique are easy to obtain when a utility, particularly in developing countries, is embarking on a master plan development of their electricity infrastructure as was the case for the examples provided above. More established utilities such as the UK's National Grid Company may not embark on this exercise as was pointed out in Section 2 of the paper in view of the need to carry out a full scale network planning (involving generation, transmission and distribution). The impact of network security ( $\mathrm{N}-1$ contingency analysis) was included in the determination of the transmission investment costs in Section 4.1 as well as positive, negative or zero circuit growth rates for the distribution example described in Section 4.2. It therefore covers the enhancements described in [3-5] in their University of Bath/Western Power Distribution Company LRIC model.

The calculation of the LRMC is the first stage of a tariff study [12] though the figures need to be adjusted to meet the government's objective of social welfare.

Finally, it must be mentioned that the demand forecasts in MW were firstly determined before the studies reported in this paper (as shown in Table 2 for transmission network and Table 3 for distribution network). In determining the future demand forecasts [14], a subject outside the scope of this paper, the following parameters were included as inputs in the formulation of the mathematical model:

- Historical input data (such as generation, losses etc)

- By consumer category (such as sales, number of customers etc)

- External data (such as GDP figures; real prices; population data and market surveys)

- Forecast input data such as population; prices; income; government policy; master plans; electrification programmes; loss reduction measures; metering changes; demand side management measures etc.

\section{REFERENCES}

[1] Yu, C. W. and David A.K., "Integrated Approach to Transmission Services Pricing", IEE Proceedings on Generation, Transmission, and Distribution, 146, 1999, pp. 225-226.

[2] Turvey R., "What are Marginal Costs and How to Estimate them?" Technical Paper 13, Centre for the Study of Regulated Industries, University of Bath, Bath (2000).

[3] Li, F and Tolley, D.L., "Long-Run Incremental Cost Pricing Based on Unused Capacity". IEEE Trans on Power Systems, 2007, pp 1683-1689.

[4] $\mathrm{Gu}, \mathrm{C}$ and $\mathrm{Li}, \mathrm{F}$., "Long-run incremental cost pricing considering uncertain future load growth". IEEE Power \& Energy Society General Meeting, 2009, pp 5071-5075. 
Table 5: Comparison of Results

\begin{tabular}{|c|c|c|c|c|c|}
\hline \multirow{2}{*}{ Case Study } & \multirow{2}{*}{ Upgrade } & \multicolumn{3}{|c|}{ Marginal Incremental Costs (MIC) in $\$ / \mathrm{kW}$} & \multirow{2}{*}{$\operatorname{AIC}(\$ / \mathrm{kW})$} \\
\hline & & Technique 1 & Technique 2 & Technique 3 & \\
\hline \multirow{5}{*}{ Case Study 1} & Upgrade 1 & $=$ & $=$ & $1,028.78$ & \multirow{5}{*}{259.56} \\
\hline & Upgrade 2 & -80.92 & -153.21 & 196.36 & \\
\hline & Upgrade 3 & 38.05 & 192.49 & 195.34 & \\
\hline & Upgrade 4 & 65.91 & 402.19 & 240.54 & \\
\hline & Upgrade 5 & -39.25 & -238.75 & 135.55 & \\
\hline \multirow{5}{*}{ Case Study 2} & Upgrade 1 & $=$ & $=$ & 454.33 & \multirow{5}{*}{495.80} \\
\hline & Upgrade 2 & 15.20 & $=$ & 471.05 & \\
\hline & Upgrade 3 & 57.88 & 791.91 & 496.84 & \\
\hline & Upgrade 4 & 69.68 & 726.86 & 521.10 & \\
\hline & Upgrade 5 & 86.72 & 651.22 & 540.16 & \\
\hline
\end{tabular}

[5] Heng, H. Y. and Li, F. "Long-run incremental cost pricing for distribution network - different circuit growth rate", Proceedings of the CIRED Conference, 2009, pp 1-4.

[6] Bakirtzis A, "Comparison of two methods for longrun marginal cost-based transmission system useof-system pricing" IEE Proceedings on Generation, Transmission, and Distribution, vol. 148, 2001, pp 477-481.

[7] Malik A. S. and Al-Zubeidi, S "Electricity tariffs based on long run marginal costs for central grid system of Oman", Energy, vol. 31, 2006, pp 1703 1714.

[8] "Estimation of Long Run Marginal Cost (LRMC)"- $\mathrm{A}$ Report prepared by Marsden Jacob Associates for the Queensland Competition Authority, vol3, 2004

[9] Munasinghe, M "Principles of Modern Electricity Pricing", Proceedings of the IEEE, vol. 69, 1981, pp $332-348$.

[10] Ekwue A O and Harlow, I. "Long-Run Marginal Costing of Transmission Capacity", paper no C1-
108, Proceedings of the CIGRE Conference, France, 2008

[11] South Africa Power Networks, "Annual Pricing Proposal 2013-2014" Appendix E: long Run Marginal Cost Methodology, 24thMay 2013.

[12] Iwuagwu I N “Electricity Pricing in Less Developed Countries: Incorporating Economic Efficiency and Equity Objectives", Nigerian Journal of Technology, vol. 20, no. 1, March 2001, pp $11-18$.

[13] Musa S Y and Mbaga E.V. "Daily Nigerian Peak Load Forecasting Using Artificial Network with Seasonal Indices" Nigerian Journal of Technology, vol. 33, no. 1, Jan 2014, pp $114-118$.

[14] Feinberg, EA and Genethlion D, "Load forecasting", chapter 12 of "Applied Mathematics for Restructured Electric Power Systems", edited by Chow J H, Wu FF and Momoh J, published by Springer US, 2005, pp. 269-285. 